\title{
Academic-service collaboration in evidence-based practice
}

\author{
Susan D. Moch, Rebecka Harper, Angela Grimley, Brittney Castleman Thyssen, Teresa Coughlin, \\ Paul Schedler, Megan Behl, Rachel Philipps
}

College of Nursing and Health Sciences, University of Wisconsin-Eau Claire, United States

Correspondence: Susan D. Moch. Address: Nursing 279 University of WI-Eau Claire, WI USA. Telephone:

715-836-4889. E-mail: smoch@uwec.edu

Received: December 30, 2011

Accepted: March 4, 2012

Published: November 1, 2012

DOI : $10.5430 /$ jnep.v2n4p154

URL: http://dx.doi.org/10.5430/jnep.v2n4p154

\section{Abstract}

Through this academic-service collaboration, undergraduate students engaged with a service partner to complete evidence-based practice projects. This case report describes the process and the outcomes of the three year experience. Project outcomes were evaluated through student and staff surveys. Students completed pre- and post-project surveys that revealed increased knowledge of evidence-based practice (EBP) and increased confidence in finding evidence for practice. Student responses also indicated high satisfaction with the process. The service partner staff post-project surveys indicated a high level of satisfaction with the process, increased learning and that targeted agency outcomes had been achieved.

\section{Key words}

Evidence-based practice, Undergraduate students, Academic-service partnership, University-clinical agency collaboration, Research-practice gap, Service-learning, Academic-practice partnership

\section{Introduction}

Academic-service collaborations provide opportunities for important innovations in health care. This collaboration provided an experience in evidence-based practice (EBP) through which students learned about EBP and staff gained cost-effective access to information for practice. Student engagement in EBP projects makes a difference for both student learning and for nursing practice. Students learn about the process of EBP in real situations and this learning stimulates awareness of the importance of EBP for future practice. In addition, practicing nurses benefit by getting access to up-to-date knowledge in a cost effective manner. This case report of EBP in one service agency includes both the process and the evaluation outcomes of the three-year project.

Student involvement in EBP is increasing ${ }^{[1-4]}$ but more research and evaluation is needed. This case report, in which a service agency and an academic department collaborated on evidence-based practice projects, contributes to this growing body of knowledge related to collaborations and EBP.

Several EBP projects focusing on nursing students are described in the literature, but limited evaluation data are available on these projects. Evaluation reports include a study through which student involvement in EBP projects was favorably evaluated by clinical preceptors through a telephone survey ${ }^{[4]}$. According to Stone and Rowles, students gained experience in facilitating an understanding of the importance of EBP and at the same time, staff members were exposed to 
recent research information. Another study involved a class of undergraduate students finding and appraising research on topics identified by practitioners ${ }^{[1]}$. Practitioners then participated in research roundtable discussions to determine the applicability of the findings. Moch and Cronje ${ }^{[3]}$ used action research methodology to evaluate undergraduate EBP projects with clinical staff. These projects, involving small groups of students and staff, were evaluated favorably by staff and administrators. A recent report on partnering graduate students with a clinical agency ${ }^{[2]}$ shared policy change, practice change and conducting a research study as the outcomes of the collaboration.

This academic-service collaboration involved a faculty member (and other faculty consultants) and students from a comprehensive university. The university has a strong history of faculty-student research collaboration involving students at the undergraduate level. The service partner, Community Health Partnership, offers services to assist persons to live at home or in an environment chosen by the client. An interdisciplinary staff provides services to the clients and families to make it possible for the person to live in the chosen environment.

The undergraduate students were present in the agency for approximately five hours per week. Students found research evidence for staff based on requests. They also worked with staff on EBP projects as determined by the staff and administration and provided professional development activities for personnel.

The university professor hired, supervised and consulted with students. The professor also initiated the request for funding from the agency and maintained communication with the agency administration and staff. Students were guided in the project and provided with consultation regarding the scientific literature. When additional content consultation was needed, the professor directed students to faculty consultants with expertise on the topic.

The clinical agency administrator provided a space for students and facilitated student integration into the agency. The administrator encouraged communication between agency staff and students and gave the students feedback about their involvement with the agency.

\section{Examples of EBP projects}

Some of the EBP projects initiated over the three years of funding included: obtaining research information for agency staff; leading New Knowledge Discussion Groups, completing agency-initiated projects, and disseminating research to staff through presentations and through regional conferences or through publications.

\subsection{Obtain research-related information}

Through responding to requests for information by staff, undergraduate research assistants obtained research evidence and other best practice information with the assistance of faculty members and librarians. The students found research articles for a variety of staff including registered nurses, nurse practitioners, physicians, and administrators. During year two of the project, the research assistants received requests for 53 different topics including for example, long term use of nicorette gum, adult attention deficit disorder, complementary and alternative medicine therapies, and Lyme disease treatment for people with arthritis. The research assistants located and printed research articles, highlighted main points, and then delivered the articles to the staff members.

\subsection{Lead new knowledge discussion groups}

During the first year of student involvement, students and the professor lead New Knowledge Discussion Groups ${ }^{[5,6]}$ on topics of interest to the agency. These groups were instituted to increase learning about recent evidence on an agency-selected topic and to acquaint the staff with the university students.

\subsection{Complete agency-initiated projects}

Students worked with staff to complete agency-initiated projects. In an exemplar demonstration of the collaborative process, students and clinical staff focused on a Chronic Obstructive Pulmonary Disease (COPD) project in which two students assisted in enhancing care for clients dealing with COPD. These undergraduate students found extensive research 
information on COPD, including COPD best practice guidelines, smoking cessation research, pulmonary rehabilitation, incentive spirometry, and nutrition. In addition, the undergraduate students had the opportunity to consult with and to foster agency connections with two experts in COPD.

Another project that emerged through the collaboration with the clinical agency was an evaluation project regarding perceived outcomes of nurse/team involvement. The purpose of the project was to encourage staff reflection on how to obtain better outcome data for nursing care. After collaborating with the professor on writing a research proposal and obtaining Protection of Human Subjects approval through the university, undergraduate students made phone calls to seven registered nurses and six nurse practitioners, asking questions about practice interactions. The research assistants summarized and shared the information.

\subsection{Disseminate research/ evaluation}

The undergraduate nursing students were involved in disseminating research results and evaluation data through agency presentations, at conferences and through publications. The students presented information on identified topics to the interdisciplinary staff at educational meetings and conducted evaluations from the attendees. The staff expressed gratitude for the work of the students and staff evaluated the presentation favorably. As a result, more requests for presentations by students were received. During year three, many staff attended a meeting during which students shared information about dementia and tools for measuring cognitive function. After the session, 18 very positive evaluations were received from attendees. Students have also been involved in sharing evaluation of the projects at research conferences and through co-authoring publications.

\section{Service agency evaluation}

The three-year collaboration included evaluation of outcomes for the service agency as well as student learning outcomes. For all evaluation, Institutional Review Board Approvals for the Protection of Human Subjects were obtained. Procedures for anonymity or confidentiality as appropriate were in place. Outcomes of the EBP collaboration projects with agency staff were assessed by asking staff to complete an evaluation form. The form included questions on satisfaction with articles received, personal educational growth on the topic requested, and degree of confidence in using the information in practice. In addition, verbal feedback was solicited regarding how research articles were being used in practice. For example, one of the nurse practitioners requested and received information about complementary and alternative treatments. She subsequently created a program focusing on mindfulness and guided imagery for future implementation in the agency. This practitioner also requested information on tools that could be used to evaluate the outcomes of the program. Other feedback from the clinical agency included a statement by the clinical administrator that the staff often asked when the students would be returning to the agency because of staff interest in receiving additional research literature.

During the second and third year of the funded collaboration, evaluation forms were given to all staff members who requested articles from the research assistants. No evaluation was completed during the first year because during that pilot year, the exact plan for how students would work with staff was not known. During the second year, all staff members requesting student assistance were asked to complete the form and return it to the CHP secretary, who then forwarded the forms to the research assistants. During the third year, a form was sent with every request that was completed. The forms were purposefully very brief because of concern for staff time in completing the forms. During year two, evaluation forms were sent to 42 staff members and 21 were returned (for confidentiality, names were not requested on the forms). Although the response rate was only 50\%, many staff members made multiple requests and may have decided to fill out only one form. Findings demonstrated that staff reported high levels of satisfaction, learning and an outcome related to degree of confidence in using evidence. The survey questions and mean values of responses are reported in Table 1. All item responses were obtained on a 5 point scale from 1 (low) to 5 (high). 
Table 1. Mean Evaluative Item Responses by Year 2 Agency Staff

\begin{tabular}{ll}
\hline Item & Mean of Responses (n= 21) \\
\hline $\begin{array}{l}\text { (Satisfaction): } \\
\text { My satisfaction with the research I received on the topic I requested }\end{array}$ & 4.7 \\
$\begin{array}{l}\text { (Learning): } \\
\text { My new knowledge of the topic I requested increased }\end{array}$ & 4.2 \\
$\begin{array}{l}\text { (Outcome): } \\
\text { My degree of confidence with using the research/evidence requested increased }\end{array}$ & 4.7 \\
\hline
\end{tabular}

Note. Item responses were solicited on a five point scale. 1=low; 5=high.

Additional comments on the survey included: "excellent review," "I got what I wanted," "you really meet a need," "I felt thankful," "great to have this assistance," and "information was extremely valuable." Most of the comments were favorable although the positive comments may be especially positive because the staff seemed to enjoy having the students in the agency and they may have wanted to encourage the students through the evaluation process.

The third year evaluations were also favorable. The evaluations demonstrate satisfaction with information received. Staff members continue to discuss their interest in student involvement at CHP and frequently ask the administrator when students would be returning from school breaks. Because of the interest in the program and the outcomes perceived by administration, the agency agreed to fund the academic-service collaboration for a fourth year at a higher rate. More comprehensive evaluation by staff is planned for future projects.

\section{Student evaluation}

During the three years of the project, 31 students were involved: 9 in year 1, 10 in year 2, and 12 in year 3. The students involved in the project were hired by the faculty member according to interest in research or evidence-based practice and all but 4 of the students were sophomore, junior or senior nursing students. Five of the students were involved in the EBP projects over two years of the project and 4 students were involved for only one semester. No students were currently enrolled in a class with the professor, except three students who were involved in the projects because of a directed study or an honors project and thus were not paid research assistants. All evaluations were completed with anonymity and confidentiality as required through the Institutional Review Board so no record of which students completed the surveys is available.

During the first year of this collaboration, students evaluated the experience through a post-project survey. The first year was a pilot project and a specific plan for exactly what students would do was not formulated so no pre-survey data were collected. After the plan was in place, a post survey was instituted. But because of knowledge gained during year 1 and adding a pre survey for year 2 and 3, the original year 1 questions were modified. All surveys evaluated the undergraduate student experiences on five point scales with five being high and one being low. Areas and items measured along with the means of responses are included in Table 2.

Two open ended questions were also included and were related to what the students' learned or liked, and suggestions for improvement. Some of the comments included:

"I liked that I was able to practice and refine my research skills. I also enjoyed being able to work with practicing nurses. .." "I feel very confident in finding research articles now. It has made writing papers a whole lot easier because usually, finding good references is half the battle." "I liked working at CHP with all the nurse practitioners and looking up articles for them. I had to read all the articles I gave them so I learned ..." Suggested areas for improvement included beginning earlier in the semester, increasing mentoring time, more organization in the process and more feedback from the CHP employees. 
Table 2. Mean Evaluative Item Responses by Students

\begin{tabular}{|c|c|c|}
\hline Year and Item & \multicolumn{2}{|c|}{ Mean of Responses } \\
\hline Year One $(n=7)$ & \multicolumn{2}{|c|}{ Post-project Survey Only } \\
\hline \multicolumn{3}{|c|}{$\begin{array}{l}\text { Eight junior and senior nursing students and one other discipline student were involved in the projects and sent evaluations. } \\
\text { Satisfaction: }\end{array}$} \\
\hline Level of satisfaction with the experience & \multicolumn{2}{|l|}{3.43} \\
\hline \multicolumn{3}{|l|}{ Learning: } \\
\hline Relevance of information & \multicolumn{2}{|l|}{3.85} \\
\hline Degree of learning on chosen topic & \multicolumn{2}{|l|}{3.14} \\
\hline Degree of learning on EBP & \multicolumn{2}{|l|}{3.57} \\
\hline Degree of confidence in obtaining information & \multicolumn{2}{|l|}{4.14} \\
\hline \multicolumn{3}{|l|}{ Mentoring } \\
\hline Feeling mentored by peers or faculty member & \multicolumn{2}{|l|}{3.43} \\
\hline Year Two $(n=8)$ & Pre-project & Post-project \\
\hline \multicolumn{3}{|c|}{$\begin{array}{l}\text { Ten sophomore, junior, and senior nursing students and two other discipline students were involved in the projects and sent } \\
\text { evaluations. }\end{array}$} \\
\hline Knowledge of EBP & 3.25 & 3.75 \\
\hline Confidence in finding evidence & 3.69 & 4.13 \\
\hline Satisfaction with the process & NA & 4.38 \\
\hline Satisfaction with mentoring by peers/faculty & NA & 4.38 \\
\hline $\begin{array}{l}\text { Year Three ( } n=8 \text { pre- and post-project students) } \\
\text { ( } n=3 \text { post-project students only) }\end{array}$ & Pre-project & Post-project \\
\hline \multicolumn{3}{|c|}{$\begin{array}{l}\text { Ten sophomore, junior, and senior nursing students and two other discipline students were involved in the projects and sent } \\
\text { evaluations. }\end{array}$} \\
\hline Knowledge of EBP & 2.75 & 4.25 \\
\hline Confidence in finding evidence & 3.00 & 4.38 \\
\hline Satisfaction with the process & NA & 4.25 \\
\hline Satisfaction with mentoring by peers/faculty & NA & 4.25 \\
\hline \multicolumn{3}{|l|}{ Year Three $(n=3)$ students completed post survey only } \\
\hline Knowledge of EBP & & 4.25 \\
\hline Confidence in finding evidence & & 5.00 \\
\hline Satisfaction with the process & & 5.00 \\
\hline Satisfaction with mentoring by peers/faculty & & 4.67 \\
\hline
\end{tabular}

Note. Item responses were solicited on a five point scale. 1=low; 5=high.

The second year evaluation included a pre-project survey which was given to the involved students at the beginning of the first semester and the post-project survey that was completed at the end of the second semester of the academic year. The pre-project survey included questions about learning and outcomes and the post-project survey included a question about satisfaction and being mentored within the process, asking students to rate these on a five point scale. The survey questions with mean evaluation responses are displayed in Table 2.

For the post-project survey, 8 students commented on something they liked and 6 students suggested improvements. Responses from the open ended questions on what students liked included the following: "Working with CHP has made me feel like the work I am doing actually has an important purpose." "I like how there is a product from our research." "I really enjoyed taking more of a leadership role this semester. . I I also like being able to present our research and what we have been doing," and "I liked the degree of freedom I was allowed and the variety of projects." All suggestions for improvement included: "Everyone on our research team could try to communicate a little better." "Organization has been better this semester. I have been provided with more direction," "Have a limit to how many projects (for each person)...," "Have a more structured schedule at the beginning of the semester," "My project didn't move along as expected so have 1 or 2 projects that all students work on. ..," and "Offer a bit more guidance with new projects." 
Post-project evaluation surveys of the third year were very positive. Eight students completed the pre- and post-project survey and 3 students completed only the post-project survey. Students reported learning about EBP and increased confidence in obtaining evidence for practice. The responses regarding being mentored and overall satisfaction with the process were lower for the pre- and post-survey group but with the addition of the 3 post-survey students in the analysis, the numbers are similar to earlier years. The students shared more about specific learning experiences at the clinical agency during the third year such as "I learned how to better organize the information in a way that enabled our group to efficiently find articles and add more to the organized files.” In contrast to the first two years, students shared satisfaction with increased opportunities to work directly with CHP staff through e-mail, phone communication, and meeting individually with staff. Previously, most of the interaction was through written communication (sending articles through the mail) and limited feedback was received from staff. Eight of the students made suggestions for improvement and all of the comments are: four students commented on "more organization" or "more structure", "I would like to have set times to meet with my team. . . workshop with librarian”, "I was not always sure of the goals of the group. ..”, "more concrete meeting times", and "get more of a team approach going with the students early".

These issues are being addressed during year four with a focus on helping the student leaders to be mentors, involving more faculty members in the process, and encouraging student leaders to learn how to organize the tasks for the group. Also, because of increased funding for year four (from CHP and other agencies), more students are involved in projects.

\section{Conclusions}

This academic-service collaboration case report contributes to the growing body of knowledge related to student involvement in EBP projects. Through the collaboration, a professor, a clinical agency administrator and students from a partner university worked together to engage undergraduate students and community-based interdisciplinary staff in increasing the use of evidence in practice. Evaluation of the collaboration by staff and students demonstrated staff member satisfaction and student learning. This case-report is a model for other service collaborations currently underway through the university.

\section{Acknowledgements}

We thank Dr. Joan Stehle Werner for her valuable consultation and assistance in the preparation of this manuscript. We also acknowledge Community Health Partnership, Inc. for funding and the University of Wisconsin-Eau Claire Faculty/Student Research Collaboration Program for past funding and inspiration for this project.

\section{References}

[1] Dufault MA. A program of research evaluating the effects of a collaborative research utilization model. Online J of Knowl Syn N. 2004; 8 doc 3. http://dx.doi.org/10.1111/j.1524-475X.2001.00037.x

[2] Missal B, Schafer BK, Halm MA, Schaffer MA. A university and health care organization partnership to prepare nurses for evidence-based practice. J Nurs Educ. 2010; 49(8): 456-461. PMid:20438029 http://dx.doi.org/10.3928/01484834-20100430-06.

[3] Moch SD, Cronje RJ. Part II. Empowering grassroots evidence-based practice: a curricular model to foster undergraduate student-enabled practice change. J Prof Nurs. 2010; 26(1): 14-22. PMid:20129588 http://dx.doi.org/10.1016/j.profnurs.2009.03.003.

[4] Stone C, Rowles CJ. Nursing students can help support evidence-based practice on clinical nursing units. J Nurs Manage. 2007; 15(3): 367-370. PMid:17359437 http://dx.doi.org/10.1111/j.1365-2834.2007.00713.x

[5] Moch SD, Cronje RJ. New knowledge discussion groups: Counteracting the common barriers to evidence-based practice. Worldviews Evidence-Based Nurs. 2007; 4(2): 112-115. PMid:17553112 http://dx.doi.org/10.1111/j.1741-6787.2007.00091.x

[6] Chua Patel C, Moch SD, Cordes ME, Brueggen CM, Dose AM, Kinsey GC, et al. Research discussion groups: Guidelines for action. MedSurg Nurs. 2001; 10(1): 31-35. 